\title{
An analysis of CPR decision-making by elderly patients
}

\author{
Gwen M Sayers, Irene Schofield` and Michael Aziz Homerton Hospital NHS Trust, London and ${ }^{\star S t}$ Bartholomew \\ School of Nursing and Midwifery, City University, London
}

\section{Abstract}

Traditionally clinicians have determined their patients' resuscitation status without consultation. This has been condemned as morally indefensible in cases where not for resuscitation (NFR) orders are based on quality of life considerations and when the patient's true wishes are not known. Such instances would encompass most resuscitation decisions in elderly patients.

Having previously involved patients in CPR decisionmaking, we chose formally to explore the reasons behind the choices made.

Although the patients were not upset, and readily decided at the time of initial consultation, on later analysing the decision-making we found poor understanding of the procedure, poor recall of information given and in some cases evidence of harm.

This may be attributed to impaired decision-making capacity of elderly hospitalised patients as previously shown, or to the discomfort precipitated by having to contemplate the apparent immediacy of cardiac arrest by these patients.

We propose that subscribing to autonomy as a general principle needs to be balanced against particular cases where distress may be caused by, or result in, diminished competence and limited autonomy.

\section{Introduction}

In recent guidelines on withholding cardiopulmonary resuscitation (CPR), Doyal and Wilsher draw attention to the potential clash between respect for individual autonomy and a tradition of clinical discretion which continues to deprive patients of any knowledge of their CPR status. ${ }^{1}$

They propose that informed consent must be obtained in the case of patients where CPR is withheld on grounds other than futility, and in cases where the clinicians do not know the true wishes of the patients.

Generally when patients are admitted to hospital they are understood to be for resuscitation as part of

\section{Key words}

CPR decision-making; informed consent; autonomy. a duty of care unless otherwise explicitly stated. In young patients, withholding resuscitation is largely based on the chances of successful outcome being negligible, that is to say of CPR being considered futile. In America such patients are required to provide informed consent to their do not resuscitate (DNR) orders, but in this country it has been stated that consent is neither morally nor legally required under such circumstances. ${ }^{1}$

In geriatric medicine it is relatively uncommon for non-resuscitation decisions to be made on the basis of futility. Most are based on a variety of considerations such as frailty, disability, extreme old age and multiple pathology, all of which may reduce the likelihood of successful outcome but would not necessarily predict failure with certainty. ${ }^{2}$

This allows discretionary space for clinicians to decide, on the basis of their own values and principles, that resuscitation is not in the patient's interest. Such decisions may be based on the perceived poor quality of life before resuscitation, or the expected poor quality of life after resuscitation.

Further, both for this group of patients and for those for whom resuscitation may be considered a reasonable option, no clinician can be said to know a patient's true wishes without consultation with the individual concerned.

There has been a burgeoning number of studies which have supported the participation of elderly patients in CPR decision-making. Such studies have been questionnaire-based and have sought to assess patients' attitudes regarding their resuscitation preferences. These studies have shown that most patients want to be consulted regarding CPR decision-making, most desire CPR, ${ }^{37-9}$ most are not disturbed by the consultation, ${ }^{57}$ and many want to make their own decisions.

However, none of the studies has indicated whether the patients' preferences had been used in any way in the recorded CPR status although there is clear evidence of poor concordance when comparing the patients' preferences with those of the clinicians. ${ }^{5-9}$ In an American study which considered hypothetical outcomes, $25 \%$ of elderly patients questioned said they would not opt for CPR even if there were $100 \%$ chance of survival. ${ }^{10}$ 
Although the guidelines ${ }^{1}$ have stressed the need to obtain consent for DNR where futility is not the issue (assuming the patient can then indicate a preference for resuscitation, which would be respected) it seems that a simpler approach would be rather to ask the patient whether he/she wants resuscitation. The same would apply to those patients whose true wishes are not known which, from the evidence derived from the above studies, would be a fair proportion of elderly patients.

When treating acutely ill elderly patients, we have found that there are few who, at the time of admission, are well enough to be consulted or be able to decide. Less than $50 \%$ of the patients admitted were able to participate in decision-making in the only British study which determined the views of acutely ill patients. ${ }^{9}$ However, following the acute phase of illness most elderly patients spend a further 7-14 days in hospital prior to discharge. Some elderly patients spend months in hospital. These patients by necessity still require a CPR status.

On our service we have been approaching such competent patients, whose discharge was not imminent, to gauge their resuscitation wishes. It was made clear to these patients that such decisions had been formerly made by the doctors and if they so wished we would still decide. However, if they wanted to choose their own CPR status, we would implement their choice. On this basis we changed a number of the resuscitation orders held by such patients.

We found that none of the patients was upset by the consultation. Most made their own decision, and those choosing not to be resuscitated usually elaborated their answers unasked, with reasons such as, "No, I'm old and tired of life", or "No, definitely not. I have nothing to live for". The patients who wanted resuscitation were less specific, simply replying in affirmative terms.

We therefore chose to examine the reasons patients may have for their resuscitation preference and to see whether decision-making correlates with measurable anxiety or depression ratings using the Hospital Anxiety and Depression scale (HAD). ${ }^{11}$

Since CPR decision-making implies informed consent, we decided to measure the degree to which the patients were informed, whether their reasoning was consistent with their beliefs and whether their decision was based on such reasoning. We were interested in whether the choice was stable or whether a change had occurred one week after decision-making.

\section{Methods}

Patients with a mental test score of $>8$ on an Abbreviated Mental Test ${ }^{12}$ were eligible for the study. However, we excluded patients whom we considered overtly anxious or depressed, or whom we thought might be upset at participating in such decision-making. The patients were interviewed $\frac{c}{\overline{0}}$ during the rehabilitation phase of their illness when medically stable, usually within 2-7 days after admission to hospital.

They were initially approached by the registrar? responsible for their care (MA) in order to obtains? their preference regarding CPR. It was explainedo that "occasionally patients have a cardiac arrest.음 This means that the heart stops beating and, as no $\overline{\bar{n}}$. blood is pumped around the body, death occurs. In $\frac{1}{2}$ hospitals we usually try to start the heart up again byo using various techniques", and described weres cardiac massage, bag mask ventilation, drug therapy $\vec{P}$ and defibrillation. "In about one out of ten cases of $\vec{\omega}$ cardiac arrest we manage to start the heart up again. $\omega$ The procedure itself may have complications such as broken ribs and sometimes brain damage. would like to ask you whether you would like us tow try and start the heart up again if you had a cardiaci arrest?"

The patients were reassured that this was noto expected in their case but that their opinion was. important in letting us know what they wanted done for them and that we would abide by it.

The HAD testing was done two or three days later.

One week after the initial interview the patientse were approached by one of us (IS) who obtained informed consent in order to discuss with them reasons for their CPR decision and their recall of information provided by MA. These interviews wefeo taped. The patients were asked whether theyo remembered discussing CPR with the doctor, what was said, what they decided, the reasons for their decision and whether they still stood by their decision.

\section{Results}

Nineteen patients entered the study, 14 females and 5 males. Ages ranged from 73-94. Mean age 83.

Our CPR decisions, based on the likelihood of a successful outcome, favoured CPR in 18 of the patients. In one case (LH) we would have chosen not to resuscitate the patient because of underlyingor heart disease and her bed-bound state, but note. because of a predictably futile outcome.

Eighteen patients were able to make their own decision and one patient was unsure. Three of the्ञ patients' decisions differed from ours. Unsolicited ${ }^{\omega}$ comments were made by all of the patients at the time of the initial interview, and these are recorde in the table. No patient appeared distressed at the initial interview.

The HAD questionnaire was administered to $15^{\circ}$ of the patients and the results are tabulated. A scor of seven or less indicates non-cases, scores of eight tof ten indicate doubtful cases and scores of 11 or more indicate definite cases. Using this scale, two patients present as definite cases of depression, two as 
Table Analysis of CPR decision-making by elderly patients

\begin{tabular}{|c|c|c|c|c|c|c|c|c|}
\hline \multirow[b]{2}{*}{ Patient } & \multirow[b]{2}{*}{ Age } & \multirow{2}{*}{$\begin{array}{c}A M T \\
\text { score }\end{array}$} & \multicolumn{2}{|c|}{ HAD score } & \multirow{2}{*}{$\begin{array}{l}\text { Patient } \\
\text { Decision }\end{array}$} & \multirow[b]{2}{*}{ Unsolicited reasons given by patients at first interview } & \multirow{2}{*}{$\begin{array}{l}\text { Stability } \\
\text { of choice }\end{array}$} & \multirow{2}{*}{$\begin{array}{c}\text { Recall } \\
\text { score }\end{array}$} \\
\hline & & & Anxiety & Depression & & & & \\
\hline $\mathrm{LN}$ & 78 & 9 & 9 & 12 & FR & I think I would, I've got everything to live for & - & - \\
\hline$\overline{\mathrm{LB}}$ & 94 & 10 & 13 & 14 & $\mathbf{F R}$ & Of course I want to live & - & - \\
\hline $\mathrm{AH}$ & 83 & 10 & - & - & FR & Oh yes & - & - \\
\hline HRM & 85 & 10 & 7 & 6 & $\mathbf{F R}$ & I think so & - & - \\
\hline LH & 80 & 10 & 7 & 12 & FR & I suppose so & - & - \\
\hline$\overline{B D}$ & 83 & 9 & - & - & NFR & Finish me off. I've had my life. I've got little to live for & - & - \\
\hline RH & 84 & 8 & - & - & FR & I would, I've got all my friends and neighbours & NFR & 4 \\
\hline PH & 85 & 10 & 6 & 10 & $\mathbf{F R}$ & Yes but it's up to you & FR & 2 \\
\hline PP & 92 & 10 & 11 & 10 & Unsure & If I would cause aggravation I would call it a day & Unsure & 3 \\
\hline NF & 73 & 10 & 2 & 2 & FR & Oh yes & FR & 2 \\
\hline FM & 81 & 10 & 7 & 6 & FR & No not really but it's worth a try & NFR & 2 \\
\hline ME & 85 & 10 & - & - & FR & Life is important, age does not matter & FR & 1 \\
\hline EW & 93 & 10 & 7 & 7 & $\mathbf{E R}$ & I suppose so. I don't want to die yet & $\mathbf{F R}$ & 4 \\
\hline EP & 81 & 9 & 4 & 5 & FR & Yes but I'm not too sure & $\mathbf{F R}$ & 4 \\
\hline $\mathbf{R M}$ & 80 & 9 & 11 & 5 & $\mathbf{F R}$ & I don't want to die & $\mathbf{F R}$ & 0 \\
\hline FC & 86 & 10 & 8 & 4 & FR & Oh yes there is life & FR & 4 \\
\hline AS & 80 & 10 & 14 & 13 & NFR & I've got a strong heart. I feel so tired I don't want to go on & NFR & 3 \\
\hline JW & 75 & 10 & 10 & 4 & FR & I think so, where there is life there is hope & FR & 6 \\
\hline $\mathrm{KC}$ & 80 & 10 & 5 & 2 & $\mathbf{F R}$ & Life is sweet & FR & 0 \\
\hline
\end{tabular}

anxious and two had high scores for both anxiety and depression. One of these patients chose not to be resuscitated at first interview.

Six patients refused the second interview but nevertheless five made revealing comments reflecting disturbance.

LN said "I'm up to here with everything. I have no more to say. I said it all to Dr Aziz. I spent two hours with him."

AH found the question about CPR disturbing and did not want to talk any further about it. She said the subject upset her and she could not sleep that night. She wanted to block the matter out of her mind.

LB volunteered that "he (MA) was funny. Not a proper doctor. What was he talking about?" She said she had a pacemaker so her heart would not stop. "I should not be here. I've lived too long. I've been lost since my husband died."

HRM said "I don't want to answer any questions. It played on my mind and it makes me feel sick to think about it. I wish I hadn't said yes."

LH remembered talking to the doctor, but not about heart massage and refused to be further interviewed.

BD said he could remember discussion with the doctor but not the topic. When prompted he said "When you're dead that's it."

Thirteen patients were interviewed in depth regarding their recall of the information given and the reasons for their decision-making. Two patients had changed their minds from wanting CPR to not wanting it. One patient was still unsure and thought the doctor should decide. Twelve patients thought they should decide.

On testing for content recall using eight categories of content:

9/13 patients remembered that the heart stopped and could be restarted.

$10 / 13$ patients remembered about heart massage.
$5 / 13$ remembered an electric shock was used.

$2 / 13$ recalled that the procedure could be complicated by brain damage.

$1 / 13$ recalled artificial breathing.

No patient recalled the use of drugs or the chances of success.

Of the 12 patients who were able to decide, eight were debatably not providing fully informed consent. In brief:

Two patients appeared not to have understood the explanation:

$\mathrm{PH}$ said his reasons for wanting CPR were that he thought he would be helping with an experiment involving research on the heart and "Why not? It helps you, and you are helping me." When asked whether he thought CPR would help him he answered "Yes and no."

NF thought he was helping medical science by having a donor card and "allowing his heart to be taken out and fastened up this way or that. I may as well have it. Somebody's got to learn. Somebody's got to try them out."

Four patients wanted CPR without appreciating that the risks of the procedure were not consistent with their beliefs:

ME, when asked about her conversation with MA, said "He didn't tell me anything about it but asked what I thought. And I said life's happy yet and I would like to be resuscitated. The only thing is if I were to go really into a coma I'd like to be left."

EP, when asked for her reasons, said "You've got to make up your mind if it's really going to be helpful or not". When asked if the doctor had given any indication of how helpful it could be, she said "No, he was very careful not to do that so that he wouldn't put me in a spot. I decided beforehand that if anything was available to me and I needed it I'd use it."

FC said "I would want to be brought back. Where there's life there's hope even if someone is in a coma. 
I thought it was a funny question to ask. It frightened me a bit. If you can save a life, I don't care how much it costs but I wouldn't like to be a cabbage."

EW said "I've seen it on television. He asked if my heart stopped beating would I want it restarted and I said 'yes, wouldn't you?'” The interviewer asked if she remembered any risks to the procedure. The patient said, "Are there risks to it then? No I can't remember. I knew what he meant about he restarted it and I said yes but I didn't know anything about it being dangerous you know."

Two patients had no recall of the first interview.

$\mathrm{KC}$ had no recollection of cardiac massage ever having been mentioned. On being reminded she said that she thought it was all hypothetical and that God decides. However, she would expect to be helped and still chose resuscitation.

RM could not remember heart massage ever being mentioned to her. When reminded of the procedure and asked if she would still want it, she said "Yes, if it happens. I know I'm not young, but if my heart stopped something would have to be done because I have a family, two brothers I like to be with as much as I can."

Two patients changed their mind at the second interview, one of whom was upset.

RH became tearful when approached for the second interview because she could not read the consent form, never having learned to read or write. She did agree to further discussion at which time she said she wouldn't want to be brought back if she died, but would want a proper burial to be with her husband.

FM said "I first thought yes, if it's going to help after I died. But if you are already gone what's the good of fetching you back. That's what I've been thinking. When you are old what's the good of fetching you back. It would be better in a younger person."

Two patients could be said to have given consistent and informed consent.

AS said 'I don't want anyone jumping and bumping on my chest bringing me back from the dead. I live alone. When my time has come I want to go. At my age and with the pain, there's no need to come back. The decision is final. I've read a lot about it."

JW said "The doctor told me about brain damage and I think that where there's life there's hope. The brain damage is a minimal risk and with a lot of people, they would rather have an old person who is with them even in an institution or hospital where they could visit. They've still got that time with them. I think some may think they are better off dead, but most people would want it."

\section{Discussion}

Most British studies, although asking patients for their resuscitation preference, do not specify whether this preference was used in decision-making or whether the patients were necessarily aware that they were deciding on their own outcome.

One study, in which $92 \%$ of the patients wanted CPR, attributed this to the fact that the patients were: not considering their circumstances to be hypotheti-is cal. ${ }^{9}$ Yet this study, after broadly informing theo patients about CPR, without indicating the chanceso of success, obtained the data by asking four ques $\frac{\bar{\rho}}{\bar{n}}$. tions dealing with general issues pertaining to $C P R_{\square}$ and a fifth question asking "Would you wish CPR ifo you had a cardiac arrest?" These patients, in keeping? with the other studies, were happy to discuss their views. The authors do not indicate whether they $\vec{\omega}$ acted on the patients' wishes.

In our study all except one patient indicated their CPR preference and none seemed upset at the time of questioning. However, one week later six patients $s^{\omega}$ appeared to have been distressed by the decision $-\stackrel{\sim}{\sim}$ making, two patients in an unequivocal fashion? Four patients had no recollection of the discussiono regarding CPR although two continued to express a wish for active intervention.

\section{Difficulties with recollection}

In a paper by Schade and Muslin, ${ }^{13}$ in which resuscitation was thought to be a hopeless option, $\rho^{8} \mathrm{x}$ patients who were asked to consent to NFR ordesso became disturbed. In three of the patients there wifes difficulties with recollection or processing of theo information given. Some of our patients' responses气 were similar in this respect, suggesting psychological harm.

An explanation for the distress invoked by asking 3 patients to determine their own resuscitation status, which is not apparent in the questionnaire-based? studies, might be the immediacy of the possibility of cardiac arrest for this patient group. In the large 0 group studies the patients were being canvassed regarding their views, and the inclusion of their $\mathrm{CPR}_{-}^{-}$ preference amongst a wide variety of issues relating to CPR may not have been perceived by them to have much bearing on what would ultimately happen to them in the event of a cardiac arrest.

In asking patients to make CPR decisions we are subscribing to the principle of autonomy. Even ifo there is only a marginal chance of success, it may be argued that it is only the patient who ought to decide whether to accept or reject this chance.

Failure to involve competent patients in end-of $\frac{}{2}$ life decisions has been described as generally, bute perhaps not always, a form of crass paternalism. ${ }^{140}$ Paternalism is regarded as being wrong because it ${ }^{+}$ interferes with the right of individuals to controto aspects of their lives in accordance with their own values.

The exercising of autonomy requires both intel $\stackrel{\mathbb{\Omega}}{\stackrel{D}{ }}$ lectual and emotional competence as well as the opportunity for action. We would deprive a person 
of the opportunity for action by choosing for him, as one would do by non-consultation in CPR decisionmaking.

However, if an individual makes a choice, without understanding the implications of that choice, or because of emotional factors which impair judgment, that person may not be functioning with the degree of autonomy we would normally expect to be present in a competent adult.

Hospers ${ }^{15}$ points out that we can accept the truth of a moral principle, but that instances reflecting the exercise of that moral principle are empirical and hence need to be individually evaluated and can only be evaluated in terms of the agent concerned.

Hence:

1. Allowing patients to exercise autonomy in CPR decision-making is right.

2. This act is a case of the exercising of autonomy in CPR decision-making.

3. Therefore this act is right.

Premise three depends on the truth of premise two and the nature of the act will differ for different agents. As it is a false assumption to believe that all individuals are equally autonomous in their behaviour, the rightness or wrongness of the act depends on the particular case rather than the broad moral principle.

Our results tend to show that individuals manifest differing degrees of competence, both intellectual and emotional, in that some of our patients were intellectually unable to grasp the situation and others emotionally unable to deal with it. As competence and autonomy are interrelated the autonomy of decision-making in such cases becomes suspect.

Fitten and Waite ${ }^{16}$ showed the decision-making capacity of elderly hospitalised patients to be impaired when compared with a matched non-hospitalised group. Their study cast strong doubts about such patients' capacity to give truly informed consent, particularly where complex or risky treatments, such as resuscitation, were involved. They also showed that neither physicians' evaluations nor results of a mental state examination could identify the seriously decisionally impaired patients. Attention is drawn to these marginally competent patients, so that their limited autonomy can be respected and appropriate protection instituted where necessary. They accept, however, that we have no prospective means of identifying such patients.

It is a pity that elderly patients have served as the focus of this debate. This is because they are in a number of senses a vulnerable patient population. They are often chronically ill and suffer from a significant degree of unrecognised depression. Although our measures of cognitive function exclude obvious dementing disease, they do not reflect subtle memory and judgment failure and the poor educational opportunities experienced by some people born at the beginning of this century.

On the other hand this is the population in whom it appears some people would not wish for CPR whatever the outcome, and in whom CPR has poorer prospects of success, particularly when viewed against a background of general debility and multiple pathology.

Loewy points out that forcing patients to make a choice in a situation in which they would prefer not to choose, is not an exercise in autonomy, rather another type of paternalism. ${ }^{14}$ On the basis of respecting the wishes of those patients who would not want to be involved in such decision-making, perhaps some form of invitation might be provided to those entering the hospital. This would explain the existence of a resuscitation policy, and offer them the opportunity to discuss it with their doctor if they want to be instrumental in determining their own resuscitation status.

Although an obvious limitation to this study is the small number of patients entered, we believe these patients to be representative of apparently cognitively intact elderly individuals who might be thought capable of participating in their own decision-making regarding CPR.

Our results prove contrary, both in highlighting the faulty reasoning employed by some patients, and in demonstrating psychological pain which has been said to be the only justification for paternalism in these circumstances. We suggest further work directed at identifying those patients who want to be involved in determining their own CPR status, and how best to inform them, before approaching mentally alert patients (as Mead and Turnbull have proposed) in order to identify in advance those who would not desire CPR in the event of a cardiac arrest. $^{3}$

Gwen $M$ Sayers, MBBch, FRCP, is Consultant Physician in the Department of Medicine for the Elderly, Homerton Hospital NHS Trust, London, and Honorary Lecturer in the Department of Human Sciences and Medical Ethics at St Bartholomew's and The Royal London Hospitals School of Medicine and Dentistry, London. Irene Schofield, MSc (Gerontology), RGN, $R N T$, is Lecturer in Nursing Care of the Older Adult at St Bartholomew School of Nursing and Midwifery, City University, London. Michael Aziz, MBBS, MRCP, is Registrar in Medicine for the Elderly at the Homerton Hospital NHS Trust.

\section{References}

1 Doyal L, Wilsher D. Withholding cardiopulmonary resuscitation: proposals for formal guidelines. British Medical fournal 1993; 306: 1593-6.

2 McIntyre KM. Failure of 'predictors' of cardiopulmonary resuscitation outcomes to predict cardiopulmonary resuscitation outcomes. Archives of Internal Medicine 1993; 153: 1293-6. 
3 Mead GE, Turnbull CJ. Cardiopulmonary resuscitation in the elderly: patients' and relatives' views. Journal of Medical Ethics 1995; 21: 39-44.

4 Gunasekera NPR, Tiller DJ, Clements LT, Bhatt BK. Elderly patients' views on cardiopulmonary resuscitation. Age and Ageing 1986; 15: 364-8.

5 Hill ME, MacQuillan G, Forsyth $M$, Heath DA. Cardiopulmonary resuscitation: who makes the decision? British Medical fournal 1994; 308: 1677.

6 Morgan R, King D, Prajapati C, Rowe J. Views of elderly patients and their relatives on cardiopulmonary resuscitation. British Medical fournal 1994; 308: 1677-8.

7 Bruce-Jones P, Roberts H, Bowker L, Cooney V. Resuscitating the elderly: what do the patients want? Fournal of Medical Ethics 1996; 22: 154-9.

8 Liddle J, Gilleard C, Neil A. The views of elderly patients and their relatives on cardiopulmonary resuscitation. Fournal of the Royal College of Physicians of London 1994; 28: 228-9.

9 Potter JM, Stewart D, Duncan G. Living wills: would sick people change their minds? Postgraduate Medical fournal 1994; 70: 818-20.
10 Murphy DJ, Burrows D, Santilli S, Kemp AW, Tennes S, Kreling B, et al. The influence of the probability of survival on patients' preferences regarding cardio pulmonary resuscitation. New England fournal of Medicine 1994; 330: 545-9.

11 Zigmond AS, Snaith RP. The Hospital Anxiety an $\overrightarrow{\bar{\Phi}}$ Depression scale. Acta Psychiatrica 1983; 86: 1-10.

12 Hodkinson HM. Evaluation of a mental test score fof assessment of mental impairment in the elderly. $A g$ F and Ageing 1972; 1: 233-8.

13 Schade SG, Muslin H. Do not resuscitate decisions? discussions with patients. Fournal of Medical Ethicis 1989; 15: 186-190.

14 Loewy EH. Involving patients in Do Not Resuscitate decisions: an old issue raising its ugly head. fournal of Medical Ethics 1991; 17: 156-60.

15 Hospers J. Human conduct. An introduction the problems of ethics. London: Rupert Hart-Davis 1963.

16 Fitten LJ, Waite MS. Impact of medical hospitalization on treatment decision-making capacity in the elderlyi Archives of Internal Medicine 1990; 150: 1717-21.

\section{News and notes \\ Ethics and genetics}

Ethics and Genetics: Advanced European Bioethics Course, is the title of a course which will take place from 20-22 November 1997, in Nijmegen, the Netherlands. Specialists from various countries will discuss ethical aspects of genetics. Subjects will include Ethics and the Human Genome Project; Genetic counselling; Genetic screening; Human gene therapy, and Geneticization.

Lecturers will be: E Meslin (USA), P Schotsman
(Belgium), R Chadwick (UK), D Gracia (Spain), H ten Have (Netherlands). All lectures and plenary sessions will be held in English. For more information please contact: B Gordijn, $\mathrm{PhD}$, Catholic University Nijmegen, 232 Dept of Ethics, Philosophy and History of Medicine, PO Box 9101, $6500 \mathrm{HB}$ Nijmegen. Tel: 0031-24-3615320. Fax: 0031-243540254. E-mail: b.gordijn@efg.kun.nl. Internet site: http://www.azn.nl/fmw/news.htm 